\title{
Familial intracranial haemorrhage due to factor V deficiency
}

\author{
R S Wadia, S A Sangle, S Kripalaney, M Bafna, S R Karve
}

\begin{abstract}
Strokes may occur with a large number of genetic disorders. Natowicz and Kelley have reviewed the single gene disorders capable of causing familial haemorrhagic strokes. These may be classified into four groups: a) hereditary disorders affecting clotting factors or platelets; b) hereditary disease producing vascular anomaly; c) hereditary disease causing hypertension and d) miscellaneous group including neurofibromatosis, sickle cell disease and tuberous sclerosis.
\end{abstract}

As far as group 1 is concerned deficiency of all the clotting factors have been described as causing familial intracranial haemorrhage on occasion. The exception appears to be factor $\mathrm{V}$ deficiency. Though the first case of factor $\mathrm{V}$ deficiency described ${ }^{2}$ had acute bilateral blindness, intracranial haemorrhage due to factor $\mathrm{V}$ deficiency is unusual and was seen in only three cases of 58 cases reviewed by Seller. ${ }^{3}$ Natowicz and Kelley ${ }^{1}$ were unable to find any reported cases of familial intracranial haemorrhage due to factor $\mathrm{V}$ deficiency. We have been following one such family and document details in this report.

\section{Case 1}

A four year old boy was referred for mental retardation. The child had an episode of fever, vomiting and convulsions when he was three months old and which was diagnosed as meningitis. However, the CSF at that time showed xanthochromia with $100 \mathrm{mg} \%$ protein and 16000 RBCs. Coagulogram carried out at the time was normal except for the prothrombin time which was $35 \mathrm{~s}$ (control $15 \mathrm{~s}$ ). The patient was advised to have the tests repeated but had not done so. When seen by us four

and in revised form

2 January 1991.

Accepted 7 January 1991 years later the child was mentally retarded, he was able to walk with support. He was unable to talk. Deep reflexes were depressed and both plantar responses were extensor. The CT scan showed a large left hypodense lesion with ventricular dilatation due to porencephally. Coagulation tests showed factor $\mathrm{V}$ deficiency (table). His abnormal PTTK was corrected with absorbed plasma which contains factor $\mathrm{V}$ but not II, VII and X.

\section{Case 2}

Three months later the patient's seven month old sister was admitted with a history of vomiting. She had had two right focal fits ten days before admission. On the day of admission, she deteriorated and became more drowsy but without localising signs. The CSF showed xanthochromia and a CT scan showed a large left subdural haematoma. There was no history of trauma.

The haematoma was drained. She received blood transfusion at the time. The haematoma had to be aspirated twice and the patient improved. Two months later she was readmitted with right focal fits. Examination did not reveal any focal deficit. She was put on anticonvulsants. Her coagulogram also suggested factor $\mathrm{V}$ deficiency (table). She has continued to have occasional fits but is mentally normal. The family history is shown in the figure. There was a history of first degree consanguinity. The father and mother have both been investigated and all tests including prothrombin time and PTTK are normal. The third sibling died after heavy bleeding and unconciousness following an accident. No laboratory tests are available but she probably also had the same deficiency.

\section{Discussion}

Factor V (Proaccelerin, Labile factor) deficiency was first described by Owren ${ }^{2}$ in 1947. He thought the condition was not hereditary but since then several reports of hereditary factor $\mathrm{V}$ deficiency have appeared..$^{4-7}$ The inheritance is usually autosomal recessive. In addition several cases of autosomal recessive combined factor $\mathrm{V}$ and VIII deficiency have also been reported. ${ }^{8}$ The nature of the gene defect in these cases in unclear.

In 1972 Seeler $^{3}$ reviewed 58 cases of factor $\mathrm{V}$ deficiency in the world literature, collected over a period of 23 years. The commonest manifestations of this disorder were epistaxis 
(23 cases), echymosis (27 cases), oral bleeding (13 cases), and menhorrhagia (12 cases). Intracranial haemorrhage was uncommon and described in three cases only. Owren's first case started with epistaxis at the age of three and a half years and after one such bleed she lost consciousness for a while. Five days later vision was reduced and the next day she became blind with choked discs. Blindness persisted for six months, after which some vision appeared in one eye. Subsequent bleeding was in the form of epistaxis, echymoses and menorrhagia. She was seen by Owren at the age of 28 years with this and kidney bleeding. One other case with spontaneous intracranial bleed also manifested itself as blindness. ${ }^{4}$ The case of Sacks and Raccuglia ${ }^{5}$ had post traumatic intracerebral and subdural haemorrhage and died.

Another feature of congenital factor $V$ deficiency is the high incidence of associated congenital anomalies. ${ }^{9}$ These include duplication of renal pelvis, congenital heart disease, syndactyly, and hypogonadism. Our patients had no such abnormality.

Factor V deficiency may also occur as an acquired defect either alone or with multiple factor deficiency or with antibodies to factor V. Most modern reports on this deficiency deal with such cases. ${ }^{10-11}$ The involvement of several members of the same family and the onset in the first year of life virtually excludes an acquired aetiology. This example of familial intracranial haemorrhage due to factor $\mathrm{V}$ deficiency appears unique in the literature.

1 Notowicz M, Kelley RI. Mendelian etiologies of strokes $A n n$ Neurol 1987;22:175-92.

2 Owren PA. Parahaemophilia. Haemorrhage diathesis due to absence of a previously unknown clotting factor. Lancet 1947;i:446-8.

3 Seeler RA. Parahaemophilia factor V deficiency. Medical Clinics of North America 1972;56:119-25.

4 Brink AJ, Kingsley CS. A familial disorder of blood coagulation due to a deficiency of labile factor. Quart JMed (NS) 1952;21:19-31.

5 Sacks MS, Raccuglia G. Hereditary deficiency of Proaccelerin (Parahaemophilia). J Lab Clinic Med 1955;46. 98-110.

6 Friedman IA, Quick AJ, Higgins F, Hussey CV, Mickey ME. Hereditary labile factor (factor V) deficiency $J A M A$ 961;175:370-4.

7 Das KC, Mehta S. Congenital factor V deficiency in two sibblings. J Indian Med Assoc 1968;51:403-6.

8 Seibert RH, Margolius A, Ratnoff OD. Observation on haemophilia, parahaemophilia and coexistant haemiphilia and parahaemophilia. J Lab Clinic Med 1958;52:449-62.

9 Stoblman F, Harrington WJ, Motoney WC. Parahaemophilia (Owren's disease). J Lab Clinic Med 1951;38:842-5. 10 Crowell EB. Observation on a factor $\mathrm{V}$ inhibitor. $\mathrm{Br}$ Haematol 1975;29:397-404.

11 Shanahan F, Abhurajab A, Goodacrer ??, Blajchman MA. Factor V deficiency and its reversal with Gluten restriction in a patient with Celiac disease. Arch Intern Med 1983; 143:2009-10. 